\section{Abdominal pain and jaundice after colonoscopy}

An 82-year-old man underwent colonoscopy 6 months after open low anterior resection for an occlusive rectal carcinoma. The colorectal anastomosis appeared normal, and no metachronic polyps were detected. The patient developed abdominal pain and jaundice 2 days after colonoscopy. An abdominal computed tomography (CT) scan showed free fluid in the gallbladder fossa that extended into the hepatorenal recess, suggestive of a bile leak ( Fig. 1). Endoscopic retrograde cholan-

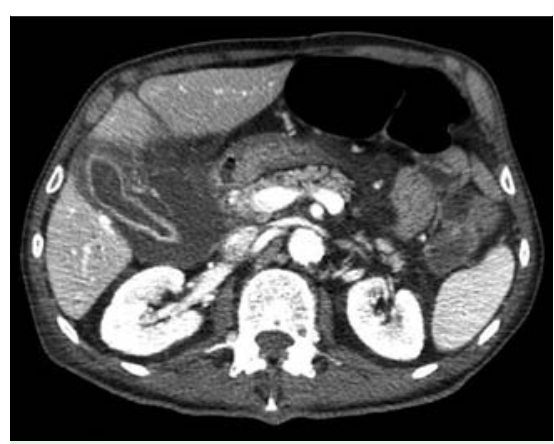

Fig. 1 Abdominal computed tomography (CT) scan in a patient who had developed pain and jaundice 2 days after undergoing colonoscopy showing free fluid in the gallbladder fossa extending into the hepatorenal recess, suggestive of a bile leak. giopancreatography (ERCP) confirmed a leak at the insertion of the cystic duct into the common bile duct (CBD; Fig. 2); the leak was managed by sphincterotomy and plastic biliary stenting.

The patient was readmitted 1 week after the biliary stenting with fever and abdominal pain. A repeat CT scan revealed a multiloculated abscess, indicative of an infected biloma. During laparoscopic drainage, multiple dense adhesions were observed to the ventral abdominal wall and between the gallbladder, transverse colon, and omentum ( Fig.3). Given their fibrous nature, the adhesions were attributed to the prior abdominal surgery. Two drainage tubes were placed and antibiotics were started; cholecystectomy was not performed. The postoperative course was uneventful, with the drainage tubes being removed after 5 days. The patient was discharged with additional antibiotic therapy and recovered well. No bile leakage was demonstrated at a follow-up ERCP 2 months later and the biliary stents were removed.

To our knowledge, no previous cases of bile leakage after colonoscopy have been reported [1]. We presume the underlying mechanism to be a rupture of the insertion of the cystic duct into the CBD caused by repetitive traction on the adhesions between the gallbladder, colon, and omentum during the colonoscopy. A similar model has been proposed for splenic rupture after colonoscopy in the presence of adhesions between the colon and spleen [2].

Endoscopy_UCTN_Code_CPL_1AJ_2AI

Competing interests: None

\section{Snauwaert, L. Vandeputte, M. Cabooter, V. De Wilde, P. Laukens, H. Orlent}

Department of Gastroenterology and Hepatology, AZ Sint-Jan AV BruggeOostende, Bruges, Belgium

\section{Acknowledgments}

$\nabla$

Intraoperative images were kindly provided by Charlotte Vercauteren, MD, and Sebastiaan Van Cauwenberghe, MD.

\section{References}

1 Ko CW, Dominitz JA. Complications of colonoscopy: magnitude and management. Gastrointest Endosc Clin N Am 2010; 20: 659671

2 Sarhan M, Ramcharan A, Ponnapalli S. Splenic injury after elective colonoscopy. JSLS 2009; 13: 616-619

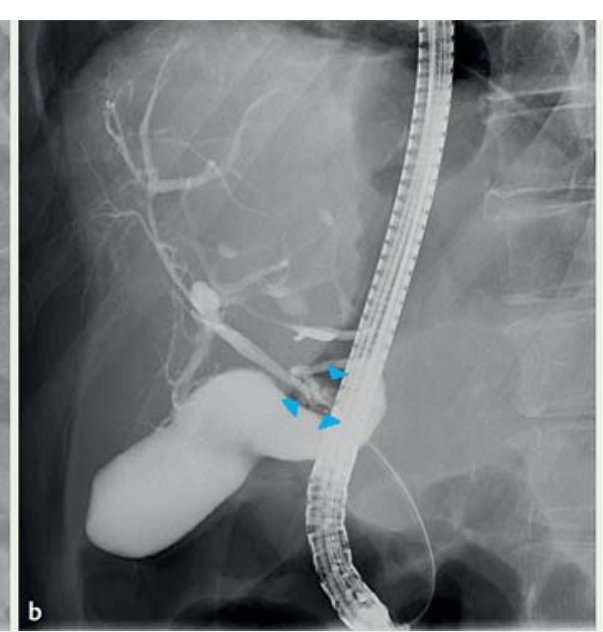

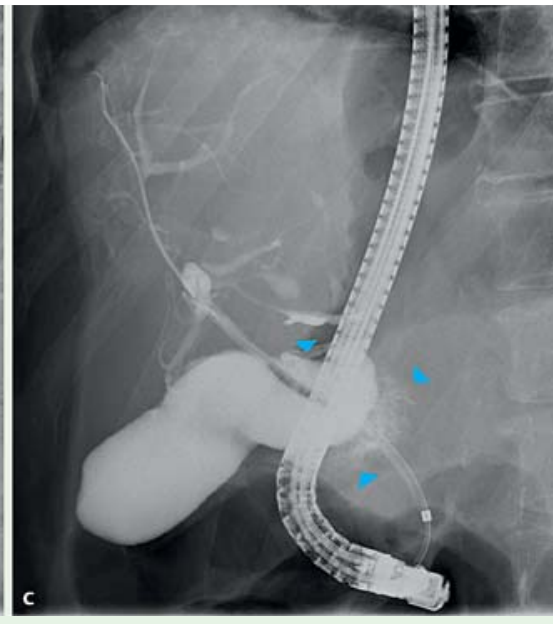

Fig. 2 Images during endoscopic retrograde cholangiopancreatography (ERCP) showing: a the initial cholangiogram; b, $\mathbf{c}$ a bile leak (arrowheads) at the insertion of the cystic duct (arrow) into the common bile duct (CBD) that became evident after progressive injection of contrast agent. 

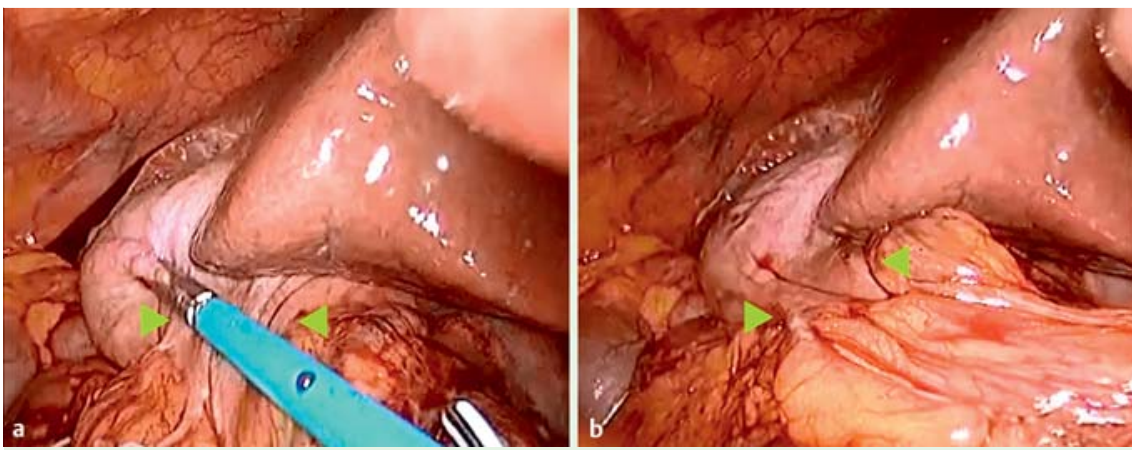

Fig. 3 Intraoperative images showing dense adhesions (arrowheads) between the gallbladder and mesocolon.

\section{Bibliography}

Dol http://dx.doi.org/

10.1055/s-0032-1326371

Endoscopy 2013; 45: E131-E132

(c) Georg Thieme Verlag KG

Stuttgart · New York

ISSN 0013-726X

\section{Corresponding author}

\section{Snauwaert, MD}

Department of Gastroenterology and Hepatology AZ Sint-Jan AV Brugge-Oostende, campus Brugge Ruddershove 10

8000 Brugge

\section{Belgium}

Fax: +32-50-452179

sehpotsirhc@hotmail.com 